\title{
FERROVIA E EXPANSÃO CAFEEIRA: UM ESTUDO DA MODERNIZAÇÃO DOS MEIOS DE TRANSPORTE.
}

\section{DIANA MARIA DE FARO LEAL DINIZ. da Universidade Federal de Sergipe.}

O presente trabalho tem como finalidade mostrar os problemas de transporte e as transformações ocorridas com a chegada da ferrovia a um centro cafeicultor do Oeste paulista - o município de Rio Claro - na segunda metade do século XIX.

A introdução de um meio de transporte moderno, substituindo os antigos muares, possibilitou o progresso do município, facilitando o escoamento da produção de uma vasta região cafeicultora e o desenvolvimento da própria cidade de Rio Claro.

A zona de São João Batista da Beira do Ribeirão Claro, situada nos "Sertões do Morro Azul", era de povoamento antigo, caminho dos que demandavam a região das minas, e ao longo do qual se tinham firmado pequenos núcleos.

"destinados quase unicamente a amparar os transportes e comunicações que se faziam por aî" (1).

Pouco a pouco foram concedidas sesmarias que se dedicaram à criação de gado e ao cultivo de cana-de-açucar, havendo uma intensificação do povoamento. Antes do café, portanto, Rio Claro já se integrava na zona canavieira paulista (2).

(1). - Prado Júnior (Caio), História Econômica do Brasil. 8. ${ }^{\text {a }}$ edição. São Paulo, Editora Brasiliense, 1963. p. 168.

(2). - Diniz (Diana M. ${ }^{a}$ de Faro Leal), Rio Claro e o Café: Desenvolvimento, Apogeu e Crise (1850-1900). Tese de Doutoramento (mimeografada). 
A 10 de junho de 1827, constituiu-se a Capela Curada de Rio Claro, tendo como seu primeiro capelão o $\mathrm{Pe}$. Delfino Barbosa, que chegara à região com os primeiros sesmeiros. O local escolhido foi de um prévio arruamento que, reforçado pela presença da capela, começou a se expandir. Mas os rioclarenses não se conformaram apenas com essa posição e pensaram em criar uma Freguesia, o que foi efetivado em 9 de dezembro de 1830. Pela Lei Provincial de 7 de março de 1845, Rio Claro foi elevado a Vila e, finalmente, por outra Lei Provincial, de 30 de abril de 1857, foi levado a Cidade (3). Este fato se deu, justamente, na época de implantação da lavourra cafeeira, pois no ano de 1853 , o município produzia 40.000 arrobas de café, superando a antiga lavoura canavieira numa média de 5.000 arrobas. Esta diferença acentuou-se de ano para ano e, uma década após, a diferença entre a produção das duas lavouras era de 158.000 arrobas, sendo a produção de açucar de apenas 21.000 arrobas. $O$ ano de 1861 , assinalou o desaparecimento da última fazenda especializada no cultivo deste produto (4).

\section{AS CONDIÇÕES DO TRANSPORTE PRE-FERROVIARIO.}

A preocupação com a circulação da riqueza era uma constante desde o período da lavoura canavieira, assunto amplamente debatido pelas autoridades locais, provinciais e, na própria Assembléia Legislativa de São Paulo, que entre os seus deputados contava com fazendeiros da região do Oeste paulista. As dificuldadas de escoamento da produção acarretavam prejuizos aos produtores de café, que viam seus lucros diminuidos, em decorrência dos altos fretes.

A implantação da cafeicultura, não trouxe, de imediato, a solução aos velhos problemas de transporte entre o interior da Província e o porto de Santos. Já nas primeiras crises de mão-de-obra, que atingiram Rio Claro no início da segunda metade do século passado, a Câmara Municipal apontava a precariedade do transporte e o seu alto preço como pontos de estrangulamento da economia agrícola, dizendo que

(3). - Marques (M. E. de Azevedo), Apontamentos Históricos, Geográficos, Biográficos, Estatísticos e Noticiosos da Provincia de São Paulo... vol. II; Rio de Janeiro, Livraria Laemmert, 1879. p. 135.

(4). - Arquivo Público" do Estado de São Paulo - TI, "Officios Diversos de Rio Claro". Cx. 396, 1845-1857, cx. 397, 1858-1865 (MSS). Arquivo Histórico e Pedagógico "Amador Bueno da Veiga" de Rio Claro, "Mappa Demonstrativo dos Produtos das Exportações do Municipio de São João do Rio Claro, no anno de 1861" (MS). 


\begin{abstract}
"remediada apenas a falta de braços, outro mal surge qual o alto preço dos transportes" (5).
\end{abstract}

Aproveitando-se da estrutura pré-existente, o café continuou sendo transportado por tropas de burros e, apesar de não se deteriorar como o açucar, as dificuldades eram grandes.

Essas tropas, em geral pertenciam às fazendas, que muitas vezes não dispunham de número suficiente de animais para transportar os seus produtos. Contratavam-se então tropas de fora, pertencentes inclusive a outros fazendeiros, na tentativa de solucionar por seus próprios meios o problema fundamental do escoamento da produção.

"Em 1865, Ibicaba possuia 1.250.000 pés de café e a Angélica 350.000. Os produtos destas fazendas eram exportados para Santos em lombo de burro n'um trajecto de 36 léguas. Para esse transporte não bastavam as suas tropas de 120 muares; e os tropeiros de fóra, como os filhos do sargento mór Marcellino de Godoy, os Athaydes, e a tropa do Barão de Cascalho iam ganhar a conducção desses productos para assim poder da: vasão a tempo e a hora" (6).

Apesar da existência de tropas, nem sempre era facil conseguir transporte até Santos, devido ao problema da carga de retorno, dificil de se obter, obrigando o café ao pagamento de um frete mais caro. $\mathrm{Na}$ análise desses problemas da cafeicultura, assim se expressou um deputado da Assembléia Legislativa Provincial:

"Porque estamos pagando $1 \$ 600$ rs., por arroba e não há conductor, que queira pegar em carga? Po:que dizem elles: 'de que vale ganhar-se... $1 \$ 600$ rs. por ar:oba na ida, se na volta não podemos ganhar nada? Em Santos só achamos carga de louça ou de fazenda cuja conducção é por demais arrisccada em semelhantes caminhos" (7).

No esforço de solucionar esses problemas, que tanto prejudicavam o maior desenvolvimento da economia paulista e, sobretudo, rio-

(5). - APESP - TI, Officios Diversos de Rio Claro, 1845-1857, cx. 396. "Officio da Camara Municipal de Rio Claro ao Ilmo Sr. Presidente da Provincia em 12 de Novembro de 1854". (MS).

(6). - Forjaz (Djalma), O Senador Vergueiro, Sua Vida e Sua Epoca (1778-1859). São Paulo, Officina do "Diario Official", 1924, p. 68. 1857 p. 349 .

(7) . - Annaes da Assembléa Legislativa Provincial de São Paulo, 
clarense, planos diversos foram sugeridos com a finalidade de facilitar o escoamento da produção cafeeira.

Em 1841, foi apresentado à Assembléia Legislativa Provincial um projeto de construção de uma estrada de carros ligando Rio Claro à cidade de São Paulo. Essa sugestão, iniciativa de Antônio Paes de Barros, Vicente de Souza Queiroz e Antônio de Souza Queiroz, teve seu teor alterado no ano seguinte, pretendendo-se realiza-lo de forma mais completa, ligando diretamente Rio Claro a Santos, isto é, os vários centros produtores ao porto de exportação.

"... ponderando maduramente a materia, se convenceram que aquelle projecto não abrangendo a linha inteira de estradas, dos pontos no mesmo indicados, até o porto de Santos para facilitar a exportação dos productos, traria somente vantagens parciaes que provavelmente não compensarão os sacrificios que fizessem a companhia com emprego de capitaes, e a Provincia com a concessão do privilegio. Por isso resolverão alargar o plano da Empresa fazendo-a compreender toda a linha de Santos até São João do Rio Claro, ramificando-a ainda para outros logares, que são centros de producção, cuja exportação é feita pelo porto de Santos" (8).

A organização de tal empresa seria muito lucrativa para a lavoura (9), mas tal projeto não foi levado adiante. Na Assembléia discutiu-se amplamente o assunto, chegando-se a propor concessão de tal privilégio a uma companhia particular, que talvez não dispusesse de capitais suficientes para a manutenção da estrada (10). Mas, pela Lei n.o 31 , de 12 de maio de 1854 , o Legislativo concedeu autorização ao Governo para a concessão da construção e sua manutenção. Entretanto, tal Lei não foi executada, pois o Governo Provincial voltava os olhos para a construção de ferrovias e resolvera

"outorgar a garantia addicional do juro de $2 \%$ à companhia, que contractar com o Governo Imperial a construcção da estrada de ferro de Santos para essa Capital, e interior" (11).

(8). - Annaes da Assembléa Legislativa Provincial de Säo Paulo, 1852-1853. p. 349 .

(9). - APESP-TI, Officios Diversos de Rio Claro, 1845-1857, cx. 39.6. "Officio da Camara Municipal de Rio Claro ao Ilmo. Sr. Presidente da Provincia em 12 de novembro de 1854". (MS).

(10). - Annaes da Assembléa Legislativa Provincial de São Paulo, 1854. p. 193 .

(11). - "Discurso com que o Vice-Presidente da Provincia Dr. Antônio Roberto de Almeida abrio a Assembléa Legislativa Provincial em 15 de Fevereiro de 1856". Annaes da Assembléa Legislativa Provincial de São Paulo, 1856. p. 256. 
Em 1859, o Barão de Rio Claro defendeu a aplicação da Lei de 1854, devido à grande necessidade da construção da estrada até Rio Claro. Esse projeto, que tambem não foi avante,

"nos daria hoje uma estrada de carros e de rodagem para se poder com facilidade exportar os generos do municipio que por ca estão demorados por falta de transporte" (12).

Um cafeicultor, em 1860, calculava que as despesas de transporte para uma produção de 9.000 arrobas, a ser transportada a uma distância de 15 léguas anualmente, chegava a 20:318\$000 réis. Mesmo sem considerar o capital imobilizado na aquisição da tropa, a despesa do fazendeiro chegava ao total de 13:918\$000 réis. E evidente que tão elevado custo de transporte diminuia os lucros do produtor, fato perfeitamente observavel pela análise de despesas e lucros dos lavradores (Quadro 1).

\author{
QUADRO 1 . \\ PROVINCIA DE SÃO PAULO: \\ DESPESAS COM TRANSPORTE DE CAFE. \\ 1860 .
}

Capital empregado na compra de 40 animais $\ldots \ldots \ldots \ldots \ldots 6$ 6:400 $\$ 000$

Juro de $12 \%$ a.a. sobre o capital ................ $768 \$ 000$

Remonta anual de pelo menos 5 animais ............. $800 \$ 000$

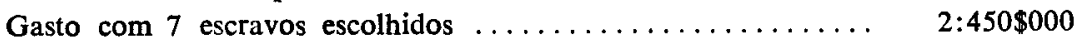

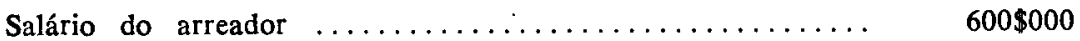

Alimentação da tropa (milho) ................ 7:300\$000

Ferragens, sustento do pessoal, barreiras, despesas e ventuais ... 2:000\$000

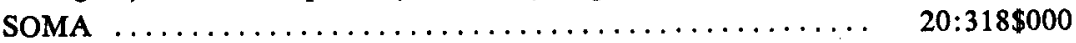

FONTE de dados brutos: Annaes da Assembléa Legislativa Provincial de São Paulo, 1860, p. 449.

Continuando a sua análise de custos, o mesmo fazendeiro demonstra que, para poder colher 9.000 arrobas, um agricultor precisava ter um cafezal de, no mínimo, 300.000 pés. Calculando-se o pé de café a 300 réis, teremos um total investido de 90 contos, somente em plantações. A esse capital deveria ser acrescido o preço dos escravos, no mínimo em número de 100 para o trabalho dos .. 300.000 pés. O capital empregado na escravaria, a um preço médio,

(12). - APESP-TI, Officios Diversos de Rio Claro, 1845-1857, cx. 396. "Resposta à Circular do Governo Provincial, de 9 de Outubro de 1857". (MS). 
alcançaria um total de 150 contos, ao qual se deveria somar o valor das terras, benfeitorias, instrumentos de trabalho, totalizando 60 contos. Finalmente, chega-se a uma soma final de 300 contos, capital que deveria ser empregado para a obtenção das 9.000 arrobas já referidas. E o fazendeiro conclui:

"Estes 300 contos no commercio, na industria, ou mesmo dados a premio rendem annualmente com toda regularidade a quantia de 30 contos, a venda do café no mercado mais próximo ao agricultor pode chegar a $5 \$ 000$ réis por arroba, que multiplicado por $9 \mathrm{mil}$, da 45 contos, dos quais deduzindo o preço dos transportes na importancia de 13.918 réis ficam 31:082\$000. Agora calcule-se os prejuizos annuais que há no pessoal da fazenda, o preço dos instrumentos de trabalho que é preciso renovar-se annualmente, etc. O lavrador que emprega 300 contos não tem que um premio de 4 ou $5 \%$ " (13).

E evidente que há um certo exagero nas conclusões a que chegou o citado fazendeiro, pois, em caso contrário, provavelmente, a agricultura paulista teria deixado de existir! Entretanto, não podemos deixar de observar que as despesas eram inúmeras, e que o custo do transporte onerava, sobremaneira, o estabelecimento agrícola.

Em decorrência dos altos fretes pagos pelos fazendeiros, tornouse forçosa uma delimitação de áreas para o plantio do café: Rio Claro, o Município em estudo, era exatamente o ponto limite, e permaneceu como "boca de sertão" até o advento da Ferrovia de Santos a Jundiaí. Segundo Taunay, ainda em 1860,

"é axiomático que plantar café além de Rio Claro, acerca de quarenta léguas de Santos, constitui ve:dadeiro absurdo. O frete tudo consome, por melhor que seja a produção" (14).

\section{A IMPLANTAÇÄO DO SISTEMA FERROVIARIO - DE SANTOS A RIO CLARO.}

Era desejo de todos, o estabelecimento de uma ferrovia que ligasse o Oeste ao porto de Santos. Já em 1855, quando da abertura das sessões da Assembléia Legislativa Provincial de São Paulo, o Pre-

\footnotetext{
(13). - Annaes da Assembléa Legislativa Provincial de Säo Paulo, 1860. pp. $449 / 450$.

(14). - Taunay (A. d'Escragnolle), Pequena História do Café no Brasil. Rio de Janeiro, s/ed., 1945. p. 236.
} 
sidente José Antônio Saraiva mostrava a necessidade de uma ferrovia que ligasse Santos à zona cafeeira mais nova da Província, isto é, o Oeste. A produção de Jundiaí, Limeira, Constituição, Rio Claro, Mogí-Mirim, Araraquara, Casa Branca, Batatais era de aproximadamente 1 milhão de arrobas de café e açucar, e com a produção de novos cafezais, deveria atingir, dentro de 5 anos, uma média de 2 milhões de arrobas. A ferrovia seria, então, extremamente util à economia desta área (15).

Neste mesmo ano, a Assembléia enviou um requerimento à Câmara dos Deputados, pedindo a concessão de linha de estrada de ferro, de Santos para o interior da Província (16) .

Mas não era geral a aceitação da ferrovia como solução dos problemas provinciais. Enquanto alguns acreditavam que, por si só, ela aumentaria a riqueza pública, desenvolvendo a indústria e facilitando o comércio, outros achavam que outras condições precisavam estar a seu lado, para trazerem o desenvolvimento esperado. A agricultura necessitava de braços em maior quantidade, técnicas mais modernas de cultivo do café e maiores facilidades de troca. Alem disso, o estabelecimento da ferrovia exigiria um capital muito grande, implicando no transporte de grandes cargas para que os juros fossem cobertos (17). Entretanto, não se se justificava o receio de falta de carga para a ferrovia, desde que seria construida justamente para servir a uma lavoura em expansão e cuja produção era limitada pela deficiência de transporte. Era de se esperar que, solucionado o problema da circulação, o volume da produção cafeeira aumentasse substancialmente, o que fato ocorreu.

Foram os britânicos, possuidores de uma tecnologia mais avançada e com uma disponibilidade de capitais que lhes permitia investir em outros paises, que estimularam o desenvolvimento de técnicas mais modernas de transporte no Brasil. Com o aumento da produção do café e da área cultivada,

"os brasileiros foram atacados cedo pela febre de assentar trilhos de aço, através do país, e os portadores desta infecção foram os engenheiros e empresários britânicos" (18).

(15). - Simonsen (Roberto), "Aspectos da História Econômica do Café", Anais do Terceiro Congresso de História Nacional. Rio de Janeiro: Instituto Histórico e Geográfico Brasileiro, 1941. p. '250.

(16) . - Annaes do Parlamento Brasileiro. Câmara dos Srs. Deputados, Sessão de 23 de janeiro de 1855. p. 36.

(17). - Annaes da Assembléa Legislativa Provincial de São Paulo. 1865-1867. pp. 80 e seguintes.

(18). - Graham (Richard), Grä-Bretanha e o Início da Modernização no Brasil, 1850-1914. São Paulo, Editora Brasiliense, 1973. p. 59. 
Em 1856, o Barão de Mauá, associado aos Marqueses de Monte Alegre e de São Vicente, obteve do governo imperial a concessão para a construção de uma estrada de ferro de Santos a Jundiaí.

“A lei n' 838 de 12/09/55 - como a lei provincial n' 495 de $17 / 3$ do mesmo ano - haviam autorizado o governo a fazer a respectiva concessão que, afinal, se concretiza no decreto $\mathrm{n}^{\mathrm{O}} 1759$ de 26/4/1856 - privilégio por 33 anos, garantia de juros de $5 \%$ sobre o capital de $£ 2.000 .000$ (19).

Em Londres, Mauá lançou o manifesto da companhia que, por isso, recebeu a denominação de São Paulo Railway Company Limited. Essa estrada foi

'projetada e financiada por Mauá, que na áspera empresa arriscou sua tranquilidade e seus haveres, para perde-los" (20).

$\mathrm{Na}$ realidade, Mauá, ligado diretamente aos interesses ingleses, e profundamente entusiasmado com a obra que tanto beneficiaria o desenvolvimento da lavoura cafeeira, procurou organizar uma companhia inglesa, tendo ele e seus sócios subscrito apenas $10 \%$ do capital e recebido 44.000 libras pela concessão e pelos estudos preliminares (21).

Em 1859, as notícias do início próximo da abertura da estrada de ferro de Santos a Jundiaí trouxeram grandes esperanças para o futuro da economia provincial. As primeiras negociações haviam sido difíceis, em virtude de certas exigências dos capitalistas ingleses, que queriam a garantia do governo imperial para o recebimento dos juros previstos (22). De fato, a Assembléia Legislativa Provincial de São Paulo promulgou uma Lei garantindo $2 \%$ de juros sobre o capital investido. A precária situação financeira da Companhia, basicamente sustentada pelo Banco Mauá, trouxe grandes prejuizos ao Barão que, mesmo assim,

"declarou depois que seu consolo pelos prejuizos sofridos consistia unicamente no fato de que sua atuação era transcendental" (23).

(19) - Visconde de Mauá, Autobiografia. Rio de Janeiro, Zélio Valverde Editora, 1941. Nota 86, p. 167.

(20). - Azevedo (Fernando de), Um Trem Corre para o Oeste. 2.a edição São Paulo, Editora Melhoramentos, s/d. pp. 45/46.

(21). - Graham (Richard), op. cit., p. 69. p. 326 .

(22). - Annaes da Assembléa Legislativa Provincial de São Paulo, 1859.

(23). - Graham (Richard), op. cit., p. 69. 
Muito tempo depois, em 1886, o Visconde de Mauá, juntamente com João Rick, tentou obter uma nova concessão para a construção de outra ferrovia, ligando Santos a Jundiaí. Evidentemente, tal projeto foi combatido pela São Paulo Railway Company, que seria altamente prejudicada pela duplicação da linha (24). Finalmente, em 15 de maio de 1860 , teve início a tão ambicionada obra, bastante dificultada nos primeiros tempos por desmoronamentos dos cortes efetuados, enchentes, etc. Apesar dos problemas iniciais, os trabalhos continuaram e, em 1864, o Conselheiro Vicente Pires da Mota informava, em seu Relatório, que a obra progredia, realizando-se serviços de capital importância. A estrada chegava aos subúrbios da capital, já se tendo gasto nela 670:704\$598. Neste mesmo ano, havia sido concluido o primeiro plano inclinado da estrada, superando a espectativa de que tal sistema não funcionasse,

\section{"sendo vencida a incredulidade de uns e de uma vez dissipa- dos os receios e prevenções de outros" (25).}

Depois de vencida a Serra, alcançar São Paulo foi muito mais facil. Esperava-se a conclusão da estrada para 1866, mas devido a uma série de dificuldades, as obras foram retardadas e só no dia 16 de fevereiro de 1867 a estrada foi entregue ao público.

Logo no início do seu estabelecimento, a ferrovia teve de reduzir os seus fretes, pois os tropeiros, que, na década de sessenta, haviam sido favorecidos com a construção de uma nova estrada através da Serra, continuaram a ter a preferência de alguns produtores, pois apresentavam, sobre a ferrovia, a vantagem do transporte "de porta a porta", e

"verificou-se que para enviar uma carga de 3.743 arrobas de Campinas para Santos, pagava-se 2:844\$000 se fosse diretamente por tropa, é 4:122\$064 se fosse por mulas para Jundiaí e daí por trem até Santos" (26).

(24) - CDI-DA, (Câmara dos Deputados), 1886 - Amarrado C, Maço 1, Pasta 1, Lata 362. "Officio do Superintendente da São Paulo Railway Company Limited, dirigido ao Presidente da Provincia de São Paulo". (MS).

(25). - Sant'Anna (Nuto), Metrópole (Histórias da Cidade de São Paulo, também chamada São Paulo de Piratininga e São Paulo do Campo em tempos de El-Rei o Cardeal Dom Henrique da Dinastia de Avis). Vol. I, São Paulo, Coleção Departamento de Cultura, 1950. p. 84.

(26) : - Morse (Richard M.), Formação Histórica de São Paulo. São Paulo, Difusão Européia do Livro, 1970. p. 206. 

tropeiros.

Com o abaixamento dos fretes, eliminou-se a superioridade dos

Se os problemas existentes foram em parte resolvidos com a chegada da ferrovia, outros surgiram, provocados pelo seu deficiente funcionamento, pois não estava atendendo completamente às exigências de tão vasta região produtora. Assim, em 1868, apareceram as primeiras reclamações e o assunto foi amplamente discutido na Assembléia Legislativa Provincial. Um deputado assim se expressava:

"Não sei que fatalidade, S. Presidente, ou mão de ferro pesa sobre esta empresa, de sorte que nos que esperavamos um futu o brilhante e grandioso trazido por este gigante do progresso, estamos ao contrario, observando que ella se vae tornando fatal ao engrandecimento e à prosperidade da Provincia de São Paulo" (27).

As dificuldades eram de natureza diversa, porem as reclamações fundamentavam-se principalmente no pequeno número de vagões $\mathrm{e}$ na sua má conservação. O suprimento do material de manutenção e aquisição de novas locomotivas se faziam muito lentamente. A impaciência dos "barões de café", que viam sua produção estocada por deficiências no transporte, transbordava nas discussőes da Assembléia. $\mathrm{E}$ assim continuava o deputado:

"A directoria da estrada de ferro, em Londres, há mais de um anno Sr. Presidente, que tem recebido reclamações para mandar locomotivas sufficientes para o transporte de generos, seus delegados anunciam todos os dias que estão a chegar quatro locomotivas para este fim e chega apenas uma.

As locomotivas que actualmente estão de tal modo danificadas que não podem conduzir, si quer os generos que se acham desitados nos armazens da cidade de Jundiaí" (28).

Estes problemas caracterizaram o início da implantação ferroviária, atenuando-se com o passar do tempo e tambem com o aparecimento de novas ferrovias a partir de Jundiaí.

Mesmo antes da inauguração do trecho inicial da estrada de ferro, cogitou-se do seu prolongamento até Campinas, pois as

(27) . Annaes das Assembléa Legislativa Provincial de São Paulo, 1868 1869. p. 287.

(28). - Ibidem. 


\begin{abstract}
"circunstâncias especiaes daquella cidade, sua producção, suas relações estreitas com os municípios productores de maior importancia do sul da Provincia, pedem que ali seja o ponto terminal de preferencia à cidade de Jundiahy, que não offerece as mesmas vantagens" (29).
\end{abstract}

Apesar disso, nesta cidade parou a ferrovia.

Pela cláusula $43 .^{\mathrm{a}}$ da concessão para a sua construção a partir de Santos, a companhia inglesa teria o privilégio no estabelecimento do prolongamento da linha férrea até Rio Claro. Entretanto, essa companhia não julgava oportuno tal empreendimento. Para os fazendeiros do Oeste, e sobretudo para Campinas, esta era uma questão vital, e, já em 1867, apresentou-se na Assembléia Legislativa Provincial um Projeto de Lei

"auctorisando a Presidencia a contrahir com o Banco do Brazil, ou com quem melhores condições offerecesse, um emprestimo sufficiente para prolongar a linha inglesa até Campinas, e caso não pudesse consegui-lo, a levantar dinheiro por meio de acções, ou como melhor lhe parecesse" (30).

Havia discussões a propósito do prolongamento da estrada de ferro, alegando-se que não seria lucrativa, salvo se houvesse uma bifurcação da linha em Campinas, seguindo um ramal para Mogí-Mirim e outro para Rio Claro. Tambem se faziam restrições a empreendimento nacional, haja visto as dificuldades de subscrição de ações da Companhia Paulista, que pretendia efetuar a ligação atẹ Campinas (31).

Apesar das dificuldades, a necessidade de prolongar-se a ferrovia para alem de Jundiaí foi mais forte. Em 1872, graças ao trabalho do seu inspirador e principal fundador, o Presidente da Província, Saldanha Marinho, a Companhia Paulista de Vias Férreas e Fluviaes chegava a Campinas. Para sua organização, contou com o decisivo apôio de fazendeiros locais e de municípios próximos, inclusive de Limeira, Piracicaba e Rio Claro (32).

(29). - Annaes da Assembléa Legislativa Provincial de São Paulo, 1865-1867. p. 58 .

(30). - "Nossas Estradas de Ferro", A Provincia de Säo Paulo, no 2, 5 de janeiro de 1875 . p. 1 . 1868. p. 1 .

(31). - Jornal do Commercio (Rio de Janeiro) $\mathrm{n}^{9} 14,14$ de janeiro de

(32) . - Matos (Odilon Nogueira de), Café e Ferrovias. São Paulo, Editora Alfa-Omega, 1974. p. 61. 
O prolongamento da ferrovia a partir de Campinas tambem era de grande interesse para estes fazendeiros, bem como para essa cidade, que veria a sua influência projetar-se mais intensamente para o interior. Para tanto, foi aberta uma concorrência, que em seguida foi sustada pelo Governo Imperial, apesar dos veementes protestos, inclusive da imprensa campineira, que assim se manifestava:

"A Provincia de São Paulo tem direitos a ser melhor considerada nas altas regiões e a não ver suas justas e nobres pretençṍes a grandes melhoramentos nullificadas pela inercia ou pela má fé dos estadistas, que dirigem os negocios publicos... a Provincia de São Paulo não pede e nem deve favores ao Estado: pelo contrario, della muitos e valiosos serviços tem recebido o paiz, e os governos, que se succederam, desde os tempos coloniaes até hoje" (33).

A fim de resolver o impasse, foram colhidas assinaturas em Rio Claro e Limeira, mas o assunto continuou pendente. Somente em 1873, por aviso do Ministério da Agricultura, ficou reconhecida a conveniência do prolongamento da ferrovia, e o Governo Provincial foi autorizado a

"prolongar a estrada de ferro de Campinas ao Rio Claro a respeito de que providenciaram as Leis $\mathrm{n}^{\circ} 44$, de 12 de Julho de 1869 e 34 de 29 de Março de 1870 da Assembléa Legislativa dessa Provincia, transmito a V. Ex. as inclusas propostas, que para tal fim me foram apresentadas, auctorisando $V$. Ex. a contractar nos termos do aviso circular de $16 \mathrm{do}$ mez próximo passado, com observância das disposições legaes que regem esta materia e da maneira mais vantajosa à Provincia e ao Estado, a realizasão dessa obra" (34).

A Paulista coube a realização da referida ligação ferroviária, com concessão obtida em 1874 (35). Embora desde 1868 se fizessem sugestões para a construção de uma estrada de segunda classe de Campinas a Rio Claro, com a finalidade primordial de apressar a ligação ferroviária, só em 1876 é que a ferrovia alcançou Rio Claro, seguindo, no entanto, o mesmo padrão, de primeira classe (36). Esta

(33). - Gazeta de Campinas, $\mathrm{n}^{\circ}$ 314, 12 de dezembro de 1872. p. 1 .

(34). - Gazeta de Campinas, $\mathrm{n}^{\circ} 330,9$ de fevereiro de 1873. p. 1 .

(35). - Annaes da Assembléa Legislativa Provincial de São Paulo, 1876. p. 64 .

(36). - Annaes da Assembléa Legislativa Provincial de São Paulo, 1868-1869. p. 24. 


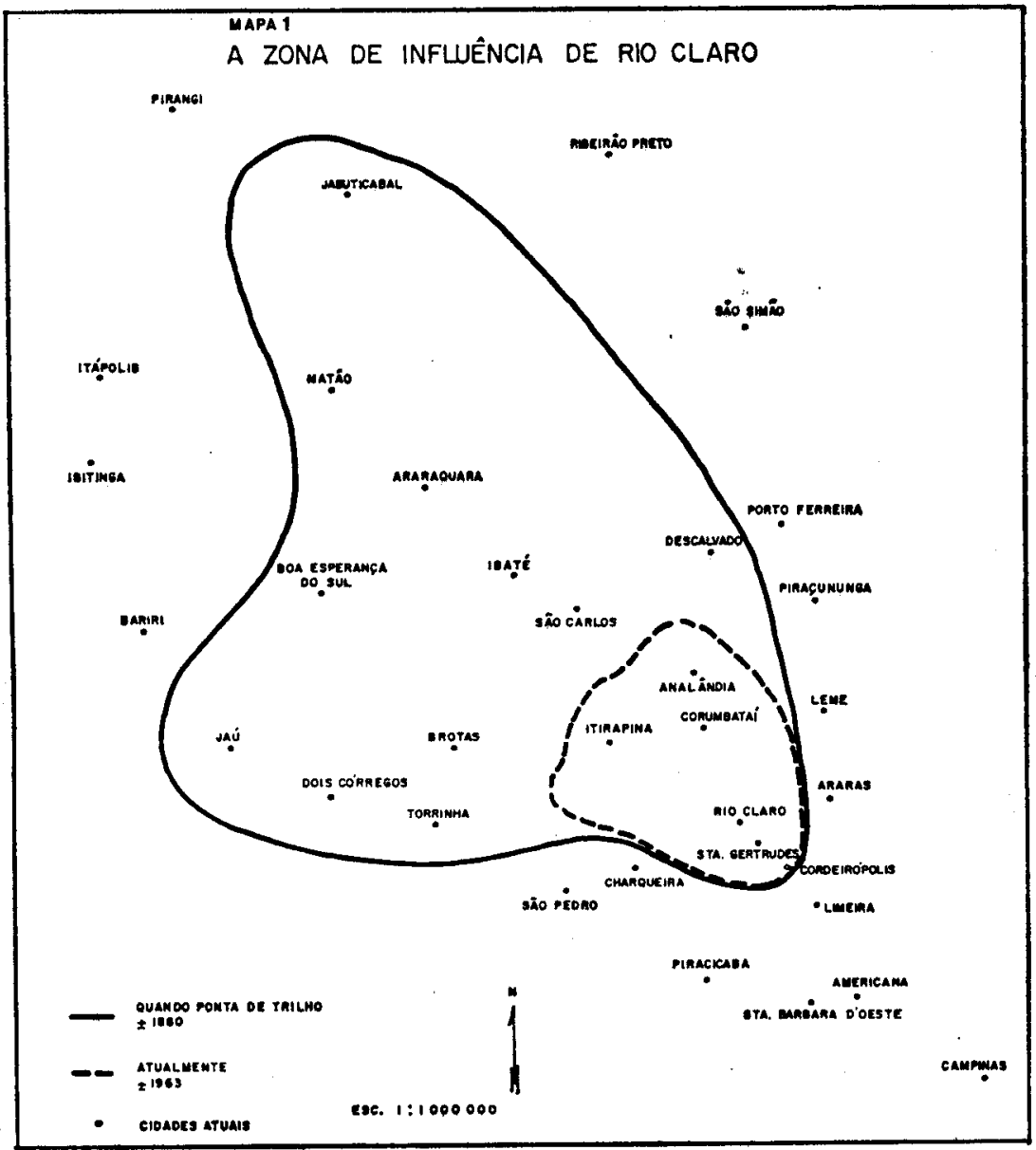

ferrovia possuia excelentes condiçōes técnicas, com raio mínimo de 301 metros. Como atingia uma zona da Província que apresentava um ritmo acelerado de desenvolvimento e a maior produção de café do Brasil, seu custo foi amplamente compensado pelos lucros. Os juros de 7\% a.a. garantidos aos acionistas pela Província só foram pagos pelo governo durante a construção, pois, assim que a estrada foi aberta ao tráfego, a renda líquida foi suficiente para cobrir aquele lucro (37).

(37). - Baptista (José Luiz), "O Surto Ferroviário e Seu Desenvolvimento" in Anais do Terceiro Congresso de História Nacional. Rio de Janeiro, Instituto Histórico e Geográfico Brasileiro, 1941 . pp. 494/501 e pp. 565/572. 
Entretanto, em outubro de 1877, a Companhia Paulista foi autorizada a cobrar uma taxa adicional de 3 réis sobre os gêneros transportados, a fim de equilibrar suas despesas. Tal fato provocou uma onda de protestos e requerimentos ao Presidente da Província para a revogação da taxa (38).

Rio Claro permaneceu como "ponta de trilho" até 1884, quando uma outra ferrovia a ligou a São Carlos do Pinhal, e esta "posição" the trouxe bastante progresso. De pequeno centro de prestação de serviços para os agricultores locais, passou a estender a sua zona de influência bem para o oeste. De fato, a zona de atuação de Rio Claro, enquanto bastante limitada ao sul e leste, devido à presença de cidades de maior expressão, como Piracicaba, Limeira e Araras, projetava-se para oeste, atingindo São Carlos, Brotas, Jaú, Araraquara e Jabuticabal (39). Com a população de toda essa área utilizando seu quadro de serviços, Rio Claro viu aumentando dia a dia sua importância regional.. Em 1883, a cidade possuia um comércio bastante desenvolvido, com 34 casas de secos e molhados, 24 casas de ferragens, 22 casas de fazendas e armarinhos, moda e chapeus, 8 sapatarias, 2 ourivesarias e 7 alfaiatarias. Contava com máquinas de beneficiar café e arroz, fábricas de cerveja e de licores. Prestava serviços médicos e educacionais, demonstrando ser já um pequeno centro cultural. Dispunha de 5 médicos, 2 dentistas, 2 professores de canto e piano, 4 farmácias, 6 colégios particulares, 6 sociedades recreativas, 1 teatro e 2 jornais (40). Atestando tambem seu grande desenvolvimento, a Assembléia Legislativa Provincial, em 1884, autorizou a Câmara Municipal de Rio Claro a contratar a construção de uma linha de bonds na cidade.

\section{A COMPANHIA RIO CLARO.}

Era de interesse do Governo Imperial e dos fazendeiros paulistas, o prolongamento dos trilhos alem de Rio Claro. Uma comissão foi encarregada de estudar os possíveis traçados de tal empreendimento, sugerindo uma linha que passaria por São Carlos, Araraquara, Taquaritinga, seguindo até Santana do Parnaiba. Consultada a Paulista, esta companhia interessou-se, apenas, pela concessão até Araraquara,

(38). - APESP-TI, Estrada de Ferro Paulista, 1870-1890. Officios Diversos. "Representação ao Presidente da Provincia do Clube da Lavoura e Commercio da Cidade de Campinas", 1877. (MS).

(39). - Almanach d'Oeste do Estado de São Paulo para 1907. Guilherme Votta Editora, São Paulo, Typographia Americana, 1907. p.. 66.

(40). - Novo Almanach de São Paulo para 1883. São Paulo, Editores Proprietários Jorge Seckler e Cia., 1882. 
assinando um contrato em 7 de junho de 1879. Afastando-se do traçado previsto originalmente, a Paulista despertou a animosidade de fazendeiros locais, vindo a desinteressar-se do empreendimento (41). O Ministério da Agricultura abriu nova concorrência para a construção da estrada, ganha pelo Barão do Pinhal que, em 1880, obteve o

"privilegio por 50 annos para construcção, uso e gozo de uma estrada de ferro que, partindo do ponto terminal da estrada de ferro Paulista, na cidade de São José do Rio Claro, Provincia de São Paulo, termine na cidade de São Carlos do Pinhal... (42).

Essa companhia não chegou a construir a planejada ferrovia e, dois anos depois, criou-se uma nova empresa, uma sociedade anônima, que obteve da primitiva

"Barão do Pinhal \& Comp. por contrato de cessão plena e absoluta todos os direitos, ações, onus e encargos adquiridos com o privilégio concedido pelo decreto 7.838 , de 1880 (43).

O Barão do Pinhal, como maior acionista, foi indicado para a presidência da primeira diretoria da nova companhia. Apesar da primeira iniciativa ter sido daquele, o Visconde do Rio Claro tambem participou ativamente da obra, pois quando do seu falecimento, em 1884 , exercia o cargo de presidente, sendo profundamente lamentada a sua perda

"pois que todos bem conhecem e comprehendem que a pessoa d'elle era a alma, acção e o motor p:incipal da existencia desta companhia. D'elle dimanaram todas as forças para a sua organisação e engrandecimento, seus companheiros de directoria não eram mais do que agentes do trabalho, pois que o pensamento era d'elle" (44).

A ferrovia partiria do ponto terminal da Paulista, indo até São Carlos do Pinhal e podendo prolongar-se até Araraquara e construir ramais para Brotas, Dois Córregos e Jaú. Nascia, assim, a Compa-

(41). - Matos (Odilon Nogueira de), op. cit., pp. 77/78.

(42). - Decreto $\mathrm{n}^{\circ} 7.838$, de 4 de outubro de 1880. p. 5 .

(43). - Estatutos da Companhia Estrada de Ferro de Rio Claro, 1882,

(44). - Relatorio que a Directoria da Rio Claro Offerece à Assembléa Geral dos Accionistas, no dia 31 de outubro de 1884. p. 4. 
nhia Rio Claro, a primeira ferrovia até então construida sem subvenção governamental, o que nos dá uma medida de desenvolvimento e concentração de riqueza na região. O seu capital, avaliado em .. 1.600:000\$, poderia elevar-se, com os juros, a 2.000:000\$. A sua diretoria era formada por três membros, eleitos pela Assembléia Geral dos acionistas, e o presidente era escolhido pela Diretoria, dentre esses.

No primeiro semestre de 1885 , a Companhia contava com 137 acionistas, totalizando 15.000 ações. Em 1886, com nova emissão de ações para a conclusão da estrada até Jaú, estas passaram para 21.000 e o número de acionistas para 254 . Os maiores acionistas eram o Visconde do Pinhal, com 3.607 ações, o Barão de Araraquara com 1.607, o Barão de Mello Oliveira, com 1.047 e a Viscondessa de Rio Claro, com 1.204. Somente eles perfaziam 7.835 ações, portanto mais de $50 \%$ do total, mostrando o interesse de capitalistas de outras áreas mais distantes bem como de Rio Claro. Este fato tambem vem comprovar a íntima relação entre o café e a ferrovia, uma vez que os maiores acionistas eram tambem produtores de café. Alem desses, somente existiam dois outros grandes acionistas, com mais de 500 ações cada um, e tambem ligados à economia cafeeira. Os demais variavam de 415 ações a 1 ação. Predominavam mesmo os pequenos acionistas, pois 100 deles tinham menos de 100 ações. Estes não estavam obrigatoriamente ligados à agricultura. Alguns eram profissionais liberais, padres, e até a Santa Casa de Misericórdia de Rio Claro era acionista (45). Rio Claro, que se apresentava, na época, como importante centro urbano, tinha nos quadros de acionistas dessa companhia pessoas não ligadas à agricultura cafeeira.

Observando-se a Tabela 1, vê-se que os acionistas de menos de 10 ações controlavam pouco mais de $1 \%$ do total, com um pequeno abaixamento em fevereiro de 1886 e uma ligeira elevação em dezembro do mesmo ano, quando da emissão de novas ações. Os acionistas de mais de 500 ações cada um, entretanto, tiveram diminuida sua participação no total, apesar do seu número aumentar.

De fato, controlavam $65,48 \%$ das ações em agosto de 1885 , $61,97 \%$ em fevereiro de 1886 e 49,52\% em dezembro do mesmo ano.

Os balanços apresentados pela Companhia Rio Claro, entre 1884 e 1886 , demonstram a sua excelente situação financeira, com lucros anuais crescentes. E interessante notar a grande diferença entre a receita e a despesa nos mencionados anos, destacando-se como

(45). - Relatorios Semestrais da Companhia Rio Claro, 1884-1886. 
TABELA 1 .

COMPANHIA ESTRADA DE FERRO DO RIO CLARO. GRUPOS DE ACIONISTAS.

1885-1886.

\begin{tabular}{|c|c|c|c|c|}
\hline Classes & 1885 (ago & & 1886 & zembro) \\
\hline $\mathrm{n}^{\circ}$ de aç̧ões & $\%$ acionistas & \% ações & \%acionistas & \% ações \\
\hline-10 & 40,44 & 1,31 & 33,87 & 1,33 \\
\hline-20 & 18,38 & 1,90 & 14,11 & 1,81 \\
\hline-50 & 11,76 & 2,97 & 16,93 & 5,34 \\
\hline-100 & 12,50 & 7,16 & 13,30 & 8,74 \\
\hline-200 & 6,61 & 6,63 & 11,69 & 14,53 \\
\hline-500 & 5,88 & 14,50 & 6,85 & 18,74 \\
\hline-2000 & 3,67 & 40,24 & 2,01 & 17,93 \\
\hline 2000 e + & 0,73 & 25,24 & 1,20 & 31,59 \\
\hline
\end{tabular}

fator importante da arrecadação o grande transporte de mercadorias, dentre as quais o café tinha primazia. Entretanto, não é de se desprezar a receita proveniente do transporte de passageiros, demonstrando que o desenvolvimento do Município aumentou substancialmente a circulação de pessoas (46). Ao contrário do que se poderia esperar, o tráfego de passageiros nas ferrovias das zonas cafeeiras não era pequeno. Mesmo na Companhia Rio Claro, em seu primeiro triênio, este movimento foi consideravel, indicando um certo contato entre o Município e outras áreas da Província, sobretudo a Capital . Pelo tráfego de passageiros da Seção Rio Claro, entre 1892 e 1901 comprova-se a validade da nossa primeira afirmativa, embora não possamos aferir o movimento originário de Rio Claro, pois, certamente, no total estão computados todos os passageiros originários de outras estaç̃̃es e que trafegaram pela referida Seção. Note-se que nestes totais estão excluidos os imigrantes que se dirigiam para as fazendas de café e eram transportados gratuitamente. Aliás, esta foi uma política sempre seguida pela Paulista e pela Rio Claro, no intuito de estimular o fluxo migratório.

Antes da ferrovia, as viagens eram realizadas por troles, que, após 1870 , vieram subistituir os lentos e incômodos carros de bois. Esses novos veículos facilitavam a ligação entre as cidades e encontramos, em 1873, empresas que se encarregavam do transporte de

(46). - Relatórios Semestrais da Companhia Rio Claro, 1886. 
MAPA 2

EXPANSÃo DAS VIAS FÉRREAS A PARTIR DÉ RIO CLARO, $1882-1900$

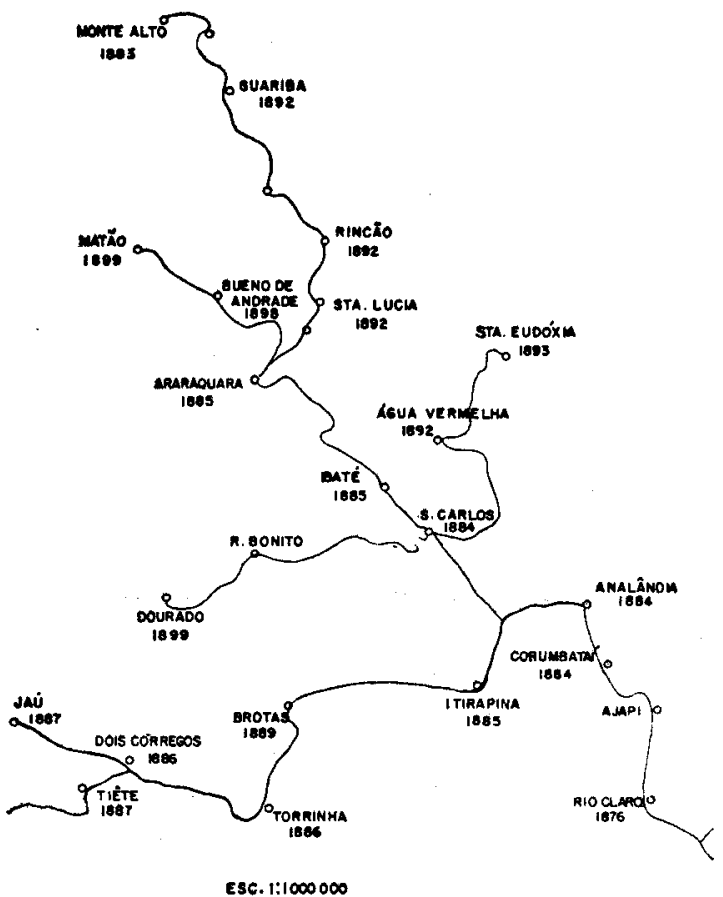

sc. $1: 1000000$

49*

passageiros entre Rio Claro, Limeira e Campinas, cobrando uma passagem de $5 \$ 000$ entre as duas primeiras cidades e de $10 \$ 000$ entre a primeira e a última (47). Em 1885, ainda èncontramos linha de troles entre Rio Claro e Piracicaba, com funcionamento diário e ao preço de $6 \$ 000$ a passagem (48).

A saudavel situação financeira da Companhia Rio Claro no seu primeiro triênio pode ser aferida pela distribuição de dividendos, sem-

(47). - A Provincia de São Paulo, $\mathrm{n}^{\circ} 2$, de 5 de janeiro de 1875. p. 2.

(48). - $O$ Tempo (Rio Claro) $n^{\circ} 300,2$ de julho de 1885. p. 2 . 
pre entre $8 \%$ e $11,3 \%$ (49). As ações da Companhia eram bastante procuradas, e o seu movimento variou de um total de 991 , no segundo semestre de 1884 , para um total de 2.955 , no período equivalente de 1886. $\mathrm{Na}$ venda das ações ocorria uma certa especulação, reafirmando o que se disse a respeito da situação equilibrada da companhia (50).

O prolongamento da ferrovia alem de Rio Claro não trouxe mais progresso para a cidade, e sim vantagens para os fazendeiros situados mais para oeste. No final da década de oitenta, fala-se em estagnação e até mesmo numa ligeira decadência.

"Rio Claro deixara de ser o emporio, o centro admirado da actividade humana em todos os seus prismas",

informa bombasticamente o Almanaque d'Oeste (51). E natural que, alem do prolongamento da ferrovia a queda dos preços do café na mencionada década, tenha contribuido para a ligeira estagnação da cidade. Os dados de impostos para a construção do sistema de captação de água demonstram a crise sofrida. Enquanto no primeiro trimestre de 1882, as casas de comércio pagaram 1:430\$000 de impostos, e as oficinas $160 \$ 000$, nos anos de 1884,1885 e 1886 , observa-se uma acentuada queda no total desses impostos, chegando a pontos mínimos em meados de 1885 e início do ano seguinte. Apenas a partir do segundo semestre de 1886 , é que se nota uma recuperação, tendo as casas de negócios recolhido 1:540\$000, e as oficinas $225 \$ 000(\$ 2)$.

De fato, a nova ferrovia visava atender aos interesses de fazendeiros locais e, principalmente, de zonas novas como São Carlos, Dois Córregos, Brotas e Araraquara, e não diretamente ao desenvolvimento urbano. Em 1886, a maior exportação de café foi, exatamente dessa zona, com um total de 817.000 arrobas, enquanto que as estações do município de Rio Claro exportaram apenas 254.000 arrobas. Aliás, analisando-se a produção cafeeira do município até o final do século comprova-se a sua diminuta importância no total de café transportado.

(49). - Relatórios Semestrais da Companhia Rio Claro, 1884-1886.

(50). - Relatório da Diretoria da Estrada de Ferro Rio Claro, relativo ao semestre de janeiro a junho de 1885 .

(51). - Almanach d'Oeste ... op. cit., p. 66. (MSS)

(52). - Livros de Atas da Câmara Municipal de Rio Claro. 1882-1886. 


\begin{tabular}{|c|c|c|}
\hline PROL & $\begin{array}{l}\text { IUNICIPIO DE } \\
\text { RIO CLARO E } \\
\text { PANHIA RIO CL }\end{array}$ & $\begin{array}{l}\text { ARO. } \\
\text { ENTO DE CAFE DA } \\
\text { 886-1898. }\end{array}$ \\
\hline Anos & $\begin{array}{c}\text { Produção Cafeeira } \\
\text { de Rio Claro. }\end{array}$ & $\begin{array}{l}\text { Total de café trans- } \\
\text { portado pela Estra- } \\
\text { da de Ferro Rio Cla- } \\
\text { ro. }\end{array}$ \\
\hline & (arrobas) & (arrobas) \\
\hline 1886 & 400.000 & 1.077 .230 \\
\hline 1892 & 498.990 & 2.690 .283 \\
\hline 1894 & 241.983 & 2.710 .704 \\
\hline 1896 & 283.620 & 3.619 .113 \\
\hline 1898 & 798.360 & 4.629 .000 \\
\hline
\end{tabular}

FONTES: Relatório da Companhia Rio Claro (1886); Relatório $n^{o} 53$ da Diretoria da Companhia Paulista de Vias Férreas e Fluviais, 1902.

TABELA 2 .

COMPANHIA RIO CLARO.

EXPORT AÇAOO DE CAFE POR ESTAÇOEES (t). 1886.

\begin{tabular}{|c|c|c|c|c|c|c|}
\hline $\begin{array}{l}\text { Algumas } \\
\text { estações } 1^{\circ} \mathrm{s}\end{array}$ & semestre & $\%$ & $2^{\circ}$ semestre & e & Total & $\%$ \\
\hline Corumbataí & 189,7 & 5,84 & 411,3 & 4,99 & 601,0 & 5,23 \\
\hline Oliveiras & 288,5 & 8,88 & 227,7 & 2,76 & $516 ; 2$ & 4,49 \\
\hline São Carlos & $1.305,6$ & $40 ; 22$ & $3.839,1$ & 46,64 & $5.144,7$ & 44,82 \\
\hline Araraquara & 569,1 & 17,54 & 995,3 & 12,09 & $1.564,4$ & 13,63 \\
\hline Brotas & 892,8 & 27,52 & $1.241,8$ & 15,08 & $2.134,6$ & 18,59 \\
\hline Dois Córregos & $-\S$ & 一 & $1.515,5$ & 18,44 & $1.515,5$ & 13,24 \\
\hline TOTAL & $3.245,7$ & 100,00 & $8.230,7 \quad 1$ & 100,00 & $11.476,4$ & 100,00 \\
\hline
\end{tabular}

§ Período anterior à inauguração da ferrovia .

FONTE de dados brutos: Relatórios Semestrais da Companhia Rio Claro, 1886.

Comparando-se as exportações de café efetuadas por algumas estaçōes no primeiro e no segundo semestres de 1886 , observa-se a grande importância de São Carlos, que passou de 40,22\% para uma exportação de $46,64 \%$. Evidentemente, essa estação não escoava apenas 
TABELA 3 .

MUNICIPIO DE RIO CLARO.

EXPORTAÇAO DE CAFE POR ESTAÇÕES (arrobas). $1884-1886 / 1900-1901$.

Exportação

Média $1884-1886$

\section{Média}

$$
1900-1901
$$

Estações

Morro Grande

TOTAL

$\%$ TOTAL

$57.870 \quad 21,08$

102.793

112.309

135.058

93.057

40.156

107.991

151.304

127.639

870.307

Cuscuzeiro $(+)$

Oliveira

46.337

16,88

$56.067 \quad 20,44$

$274.506 \quad 100,00$

$\%$
11,81
12,90
15,51
10,69
4,61
12,40
17,38
14,70
100,00

Aumento

100,00

$\begin{array}{rr}\text { TOTAL } & \% \\ 44.923 & 7,53 \\ 74.345 & 12,47 \\ 97.695 & 16,39 \\ 46.720 & 7,84 \\ 1.251 & 0,20 \\ 51.924 & 8,71 \\ 151.304 & 25,39 \\ 127.639 & 21,47 \\ 595.801 & 100,00\end{array}$

FONTE de dados brutos: Relatório no 53 da Diretoria da Companhia Paulista de Vias Férreas e Fluviais, 1902; Relatórios Semestrais da Companhia Rio Claro, 1884-1886.

a produção do município, mas tambem a das áreas vizinhas, pois São Carlos, naquele momento, desfrutava da posição de "ponta de trilho" que havia sido de Rio Claro. Essa tendência de maior exportação das estações de "ponta" pode ser observada na tabela 2 . Enquanto, em 1886, as estações de Corumbataí e Oliveiras exportaram $1.117,2$ torieladas de café, as estações do Oeste escoaram 10.359,2 toneladas! Analisando-se apenas essas seis estaçōes, observa-se que as maiores percentagens de exportação são exatamente as dos municípios situados a oeste de Rio Claro, que funcionavam como centros coletores da produção das áreas circunvizinhas.

Alem de escoar a produção dos referidos municípios cafeeiros, o prolongamento da ferrovia criou novas zonas cafeicultoras, como foi o caso de Jabuticabal, onde a ferrovia, e a consequente facilidade de transporte, atuaram como agentes de transformação da produção agrícola. Naquele município,

"seus antigos habitantes, oriundos em grande parte da Provincia de Minas, em vista da dificuldade de transporte pela falta de boas estradas, não cogitaram da lavoura do café e entregaramse exclusivamente, e ainda hoje em grande escala, à creação do gado vaccum e cavallar; mas à proporção que a ferrovia da Com-

(*). - Já no município de Analândia em 1900-1901. 
panhia Rio Claro foi se aproximando do município n'elle foi se introduzindo a cultura do café, cana de assucar, fumo, etc." (53).

A análise da exportação de café pelas estações de Rio Claro permite identificar as zonas de maior produção dentro do Município. Inegavelmente, era na parte norte de Rio Claro, nas zonas ocupadas pelas antigas fazendas Velha, Morro Grande, Angélica, Mata Negra, São José e outras, que, segundo os dados da Companhia Rio Claro, havia maior exportação. Nos anos de 1884,1885 e 1886, foi uma exportação sempre crescente: 658,878 e 1.067 toneladas, respectivamente, para a Estação de Morro Grande. Embora essa área continuasse com boa produção, seria superada, no futuro, por Corumbataí, Anápolis e Colônia. Em 1900 e 1901 era a Estação de Santa Gertrudes, a leste, que liderava o movimento. A menor exportação cafeeira entre 1884-1886 era a de Cuscuzeiro (Analândia), exatamente a de maior movimento no início do século. Tal fato demonstra o deslocamento do café para oeste. Ressalve-se o caso do leste de Rio Claro, já mencionado, onde grandes fazendas ainda mantinham sua produção em ricas manchas de terra roxa (Tabela 3 ). Analisando-se o aumento da exportação das estações do município, em termos das médias apresentadas em 1884-1886 e em 1900-1901, vemos que as grandes percentagens são as representativas das estações de Rio Claro e de Santa Gertrudes, em decorrência de não terem tido exportação no primeiro período considerado. $\mathrm{Na}$ realidade, a estação que apresentou grande aumento da exportação foi Cuscuzeiro, em 1901 já desligada de Rio Claro, e que passou de $13,61 \%$, no primeiro período, para $15,51 \%$ no segundo.

Depois da ligação entre Rio Claro e São Carlos, efetivada em 15 de outubro de 1884, continuou o avanço da Companhia Rio Claro. Alcançou Araraquara em 18 de janeiro de 1885 , Brotas em $10^{\circ}$ de julho do mesmo ano, Dois Córregos em 7 de setembro de 1885, Jaú, em 19 de fevereiro de 1887 (54). A ferrovia levou para essas zonas mais para oeste um grande progresso, com a possibilidade de comunicação mais fácil com os grandes centros, sobretudo com a Capital. A partir de março de 1888 , graças às mudanças efetuadas nos horários da Companhia Paulista, de modo a combinar com os da Companhia Rio Claro, tornou-se possivel realizar uma viagem de Jaú a São Paulo no mesmo dia (55).

(53). - Comissão Central de Estatistica, Relatorio A presentado ao Exmo. Sr. Presidente da Provincia de São Paulo no ano de 1886. São Paulo, Typographia King, 1888 . p. 396.

(54). - Relatórios da Companhia Rio Claro, 1884-1886.

(55). - APESP-TI, Estrada de Ferro Paulista, 1870-1890. Officios Diversos. "Officio do Engenheiro Fiscal da Estrada de Ferro Companhia Rio Claro ao Presidente da Provincia em 24 de março de 1888". (MS). 


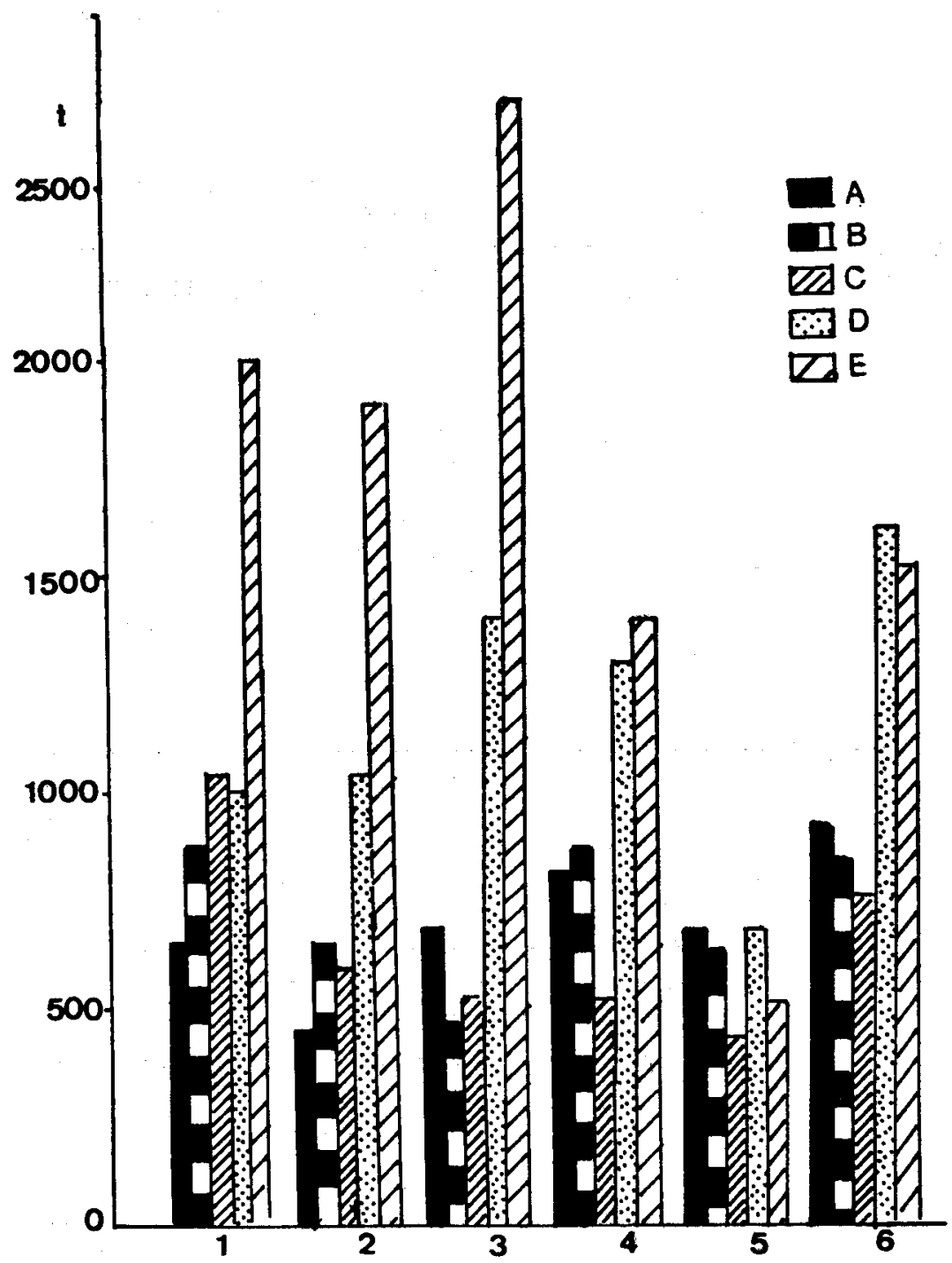

Município de Rio Claro. Exportação de café por Estações: 1) Morro Grande; 2) Corumbataí; 3) Cuscuzeiro - Anápolis; 4) Oliveiras; 5) Feijão Visconde do Rio Claro; 6) Colônia. A) 1884 ; B) 1885 ; C) 1886 ; D) 1900; E) 1901 .

FONTE de dados: Relatórios semestrais da Cia. Rio Claro e Relatório $n^{9}$ 53, da Directoria da Cia. Paulista de Vias Ferreas e Fluviaes, 1902. 
Em 1882, dois trens diários chegavam a Rio Claro, um de passageiros, proveniente de Santos, e outro misto, proveniente de São Paulo. E interessante notar que não havia trem de carga direto até Rio Claro, pois estes (três diários) ligavam Santos a Campinas. A viagem de Santos a Rio Claro era feita em 8 horas e 50 minutos nos trens de passageiros. O trecho de São Paulo a Rio Claro era percorrido em 5 horas e 50 minutos, nos trens de passageiros, e em 10 horas e 23 minutos nos trens mistos. A viagem, quer feita num ou noutro trem, sofria sempre as mesmas paradas: Santos, São Paulo, Jundiaí, Campinas, Limeira, Cordeiro e Rio Claro (56).

Contudo, apesar desse progresso, a ferrovia foi vendida, em 1889 , a uma companhia inglesa, com sede em Londres, passando a constituir a The Rio Claro Railway Company Limited.

"Interesses financeiros britânicos, liderados pelo English Bank of Rio de Janeiro, perceberam ser esta linha o início para maior expansão da vigorosa Estrada de Ferro Paulista. Eles organizaram uma empresa com um capital de 600.000 libras - logo aumentado para 850.000 - e não encontraram nenhuma dificuldade em comprar a estrada em 1889, talvez por causa dos rumores de iminente revolução para derrubar o Império" (57).

Se a ferrovia estava em franco progresso por que a sua venda aos ingleses? As incertezas provocadas pelas mudanças políticas, e as possíveis modificações na situação econômica do país, seriam suficientes para explicar a venda da próspera Companhia Rio Claro? E possivel que sim, se associarmos a isto o bom preço oferecido pelos compradores. Assim, capitais ingleses penetravam em mais uma companhia de estrada de ferro da Província, ficando a maior parte do transporte do café em mãos de companhias estrangeiras, prejudicando os interesses da Companhia Paulista.

Foi efêmera a vida da The Rio Claro São Paulo Railway Company, durando apenas 3 anos. Em 1892, depois de alguma expansão, foi vendida à Companhia Paulista de Vias Férreas e Fluviais, em troca de

"ações preferenciais da Companhia Paulista avaliadas em... 2.750.000 libras. Estradas de ferro transportadoras de café, poderiam evidentemente proporcionar fortunas aos espe:tos" (58).

(56) . - APESP-TI, Estrada de Ferro Paulista, 1870-1890. Officios Diversos. "Horario da Companhia Paulista. Inicio em 14 de fevereiro de 1882'. (MS)

(57). - Graham (Richard), op. cit., p. 67.

(58). - Ibidem. 
Realmente, mesmo levando em conta a ampliação durante o período inglês, o lucro obtido na venda da companhia foi imenso. Em três anos, uma diferença de preço, de 1.950.000 libras!

Durante o controle inglês, houve insuficiência de transporte, ficando grande quantidade de café nas estações, o que causava descontentamento entre os produtores, prejudicados, novamente, pelos problemas advindos da precariedade dos meios de transporte. Fazendeiros que tinham sua produção estocada nos armazens da The Rio Claro São Paulo Railway Company, reclamavam pelos jornais da região da deficiente capacidade de transporte da ferrovia. Em 1890, uma das críticas foi respondida pelo Inspetor Geral da Companhia, acusando a Paulista de não colocar um número suficiente de vagões para o transporte do café (59). A produção de café se processava em ritmo acelerado, necessitando de um número cada vez maior de vagões transportadores para o seu escoamento até Santos. Dizia-se, inclusive, que

"a cerca de 3 mezes as Estações regorgitam de sacas de caffe, os chefes se recusam a receber mais por não terem onde recolher, o que tem dado lugar a serios conflictos e a geral clamor dos productores e do publico" (60).

O problema, na realidade, era tambem decorrente de um fracionamento de redes de circulação, não havendo um entrosamento perfeito entre as diversas companhias que proporcionavam a chegada do produto ao porto. Com a incorporação da Rio Claro à Paulista, que pagou o seu preço em ouro, foram solucionados os problemas. Apesar do grande investimento, a Companhia Rio Claro compensava todos os esforços, não só em termos financeiros, mas tambem de projeção para o interior. De fato, sem a Rio Claro a Paulista estava barrada em seu desenvolvimento, e a renda líquida daquela compensava os encargos da dívida (61).

Nem todos os problemas de circulação de mercadorias decorriam de aspectos falhos apresentados pelas ferrovias. Os municípios cafeicultores abrangiam áreas muito extensas, distantes dos trilhos, o que dificultava o deslocamento da produção. $\mathrm{Na}$ realidade, eram necessários ramais dessas ferrovias, ou outros meios de transporte, ligando as zonas mais distantes à seção principal. Pensava-se na solução desses problemas mediante a construção de linhas de bonds, voltando-se

(59). - Diario do Rio Claro, n9 1134, 23 de setembro de 1890. p. 2. (60). - CMRC - "Acta da 22. a Sessão Extraordinária, em 6 de dezembro de 1890." Livro no 18, 1890-1891. (MS).

(61). - Relatório $n^{\circ} 53$ da Diretoria da Companhia Paulista de Vias Férreas e Fluviais, 1902. p. 17. 
a antigos projetos característicos do período pré-ferroviário, que ligassem as estações às zonas de mais dificil acesso nos municípios. Em 1890, há solicitação, aprovada pela Câmara Municipal de Rio Claro, um ano depois, de uma concessão para exploração de uma linha de bonds

"que partindo da Cidade de São Carlos do Pinhal e passando pela Estação do Morro Pellado (linha ferrea do Rio Claro) vá terminar na Estação da Charqueada, da linha ferrea da Companhia Ituana..." (62).

A linha seria de tração animal ou a vapor e poria em comunicação os referidos pontos.

Esta tentativa de construção de novas vias de circulação decorria do desenvolvimento agrícola de áreas de grande produção cafeeira, e não atingidas pela ferrovia, e que dessa forma se transformariam em áreas mais rendosas.

a zona mais importante da lavoura do Districto do Itaquery é aquella que se destaca para os lados da Villa de São Pedro, sendo as estradas de rodagem pessimas e intransitaveis no tempo das aguas pluviaes por que aquella parte deste municipio permaneceo sempre como que esquecida... attento a distancia que a separa desta cidade e a sua proximidade a outros povoados para onde faz o commercio: nestas condições a pretendida linha de bons chamara para esta cidade aquelles seus municipios proporcionando-lhes os meios de facil accesso para suas pessoas e productos de sua lavoura desde que a mesma linha se aproxima d'aquella zona tanto quanto lhe foi possivel" (63).

Esta linha de bonds solucionaria o problema de escoamento do café, que permanecia nas estações da Companhia Rio Claro, sem encontrar transporte.

"A Companhia Rio Claro não comporta o trabalho que se acumula no tempo da colheita do caffé, a Companhia Ituana que chega com sua linha até a Charqueada, faz o seu trabalho suave sem duplicidade de trem rodando por servir a uma zona pouco productora de caffé que é a lavoura demais pezo e trabalho.

(62) . - CMRC - “Acta da 22. a Sessão Extraordinária, em 6 de dezembro de 1890". Livro 18, 1890-1891. (MS).

(63). - Ibidem. 


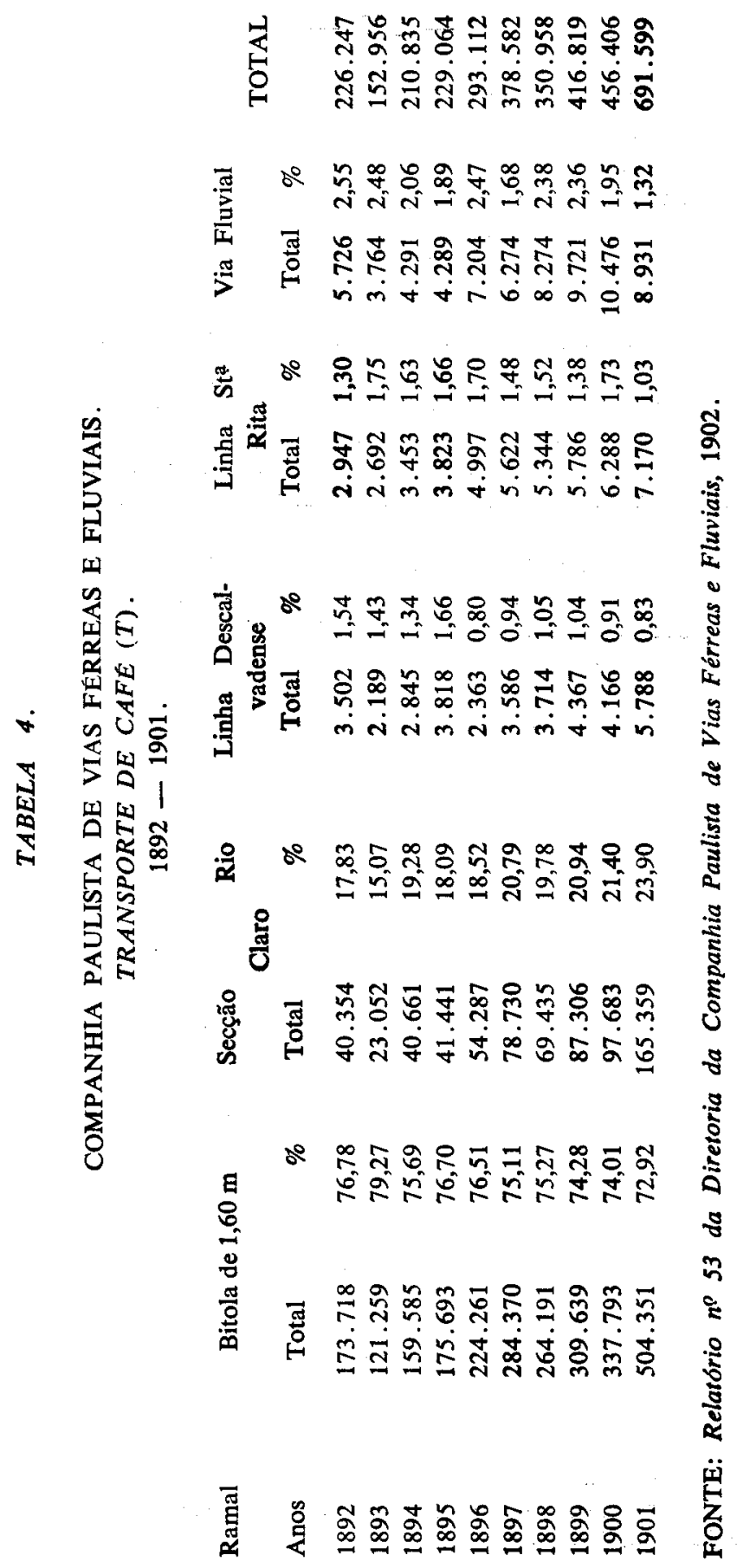


Em taes circunstancias tera a lavoura o recurso de servir-se da linha de bonds, projectada pelos supplicantes remettendo os seos productos para a Estação de Charqueada, e d'ali pela Ituana até Jundiahy, onde a Companhia Ingleza de Estrada de Ferro pelos recursos immensos de que dispõe não deixa parar as cargas para ali transportadas" (64).

Com a Paulista, os problemas mais graves foram solucionados, não se observando mais reclamações, uma vez que esta aumentou consideravelmente o número de locomotivas e vagões, construiu novos edifícios e concluiu as obras das linhas adquiridas ainda em construção (65). Era imensa a capacidade de transporte da ferrovia agora integrada. (Tabela 4). Voltam novamente a influenciar os agricultores do Município, que nela possuiam ações. Sendo ligados diretamente à lavoura cafeeira, procuraram solucionar os problemas que a prejudicavam. Desse modo, a Paulista continuou a satisfazer as necessidades dos agricultores rioclarenses.

(64). - Ibidem.

(65). - Relatório no 53 da Diretoria da Companhia Paulista de Vias Férreas e Fluviais, 190. p. 20 